\title{
USO DE REDES NEURAIS ARTIFICIAIS NA PONDERAÇÃO INICIAL DA TÉCNICA AHP EM ANÁLISES DE VULNERABILIDADE DE BACIAS HIDROGRÁFICAS
}

\author{
Use of artificial neural networks in initial ponderation of AHP techniques applied \\ to analysis of watershed vulnerability
}

\author{
Marcio Augusto Reolon Schmidt ${ }^{1}$ \\ Gustavo Rodrigues Barbosa ${ }^{1}$
}

1 Universidade Federal de Uberlândia. Programa de Pós-Graduação em Engenharia Civil. Faculdade de Engenharia Civil. Uberlândia, Minas Gerais, Brasil. Av. João Naves de Ávila, 2121 Campus Santa Mônica - Bloco 1Y - CEP: 38400-902.Email:marcioschmidt@feciv.ufu.br ; gus696@gmail.com

\begin{abstract}
Resumo:
Em muitos problemas decisórios, a informação fornecida pelos tomadores de decisão muitas vezes é imprecisa ou incerta devido ao limite de tempo, a falta de dados ou capacidades de avaliar as informações disponíveis. Como forma de superar essas dificuldades, algumas pesquisas têm apresentado a aplicação da técnica Analytical Hierarchic Ponderation (AHP). Esta técnica estrutura um problema de decisão complicada em uma hierarquia de subproblemas, faz comparações par a par das informações de entrada e, a partir do ranqueamento dos resultados, permite estimar pesos para cada variável apresentada. Entretanto, reconhece-se que o ponto mais fraco do método é a ponderação inicial das variáveis de entrada, visto que o conhecimento de especialistas pode ser subjetivo e a importância relativa entre os elementos de análise pode variar. O que não se discute na literatura é a importância desses pesos e a variação da ordem no cálculo dos pesos finais. Por isso, esta pesquisa avalia diferentes cenários no contexto de vulnerabilidade ambiental comparando as variações entre as ponderações iniciais da AHP em relação a ponderação realizada por um grupo de especialistas e em relação a ponderações iniciais obtidas a partir de redes neurais como forma de minimizar a subjetividade do processo de análise.
\end{abstract}

Palavras-chave: Redes Neurais Artificiais, Fuzzy AHP, Vulnerabilidade Ambiental

\begin{abstract}
:
In many decision problems, the information provided by decision makers is often inaccurate or uncertain due to the time constrains, the lack of data or capacity to dealing with available information. In order to overcome these difficulties, some studies have shown the application of the technique Analytical Hierarchic Ponderation (AHP) in the geosciences. This technique breaks a complicated decision problem into a hierarchy of sub-problems, makes comparisons pairwise of the input information and from the results, allow estimating weights for each considered variable. However, this study recognize that the weakest point of the method is the
\end{abstract}


initial weighting of the input variables, as the expert knowledge can be subjective and relative importance of the elements of analysis may vary. In the literature, there is no discussion about the effects of these weights and their variation on final weights. Therefore, this research evaluates different scenarios, considering the environmental context of vulnerability, comparing the adjustment of initial ponderation values of common AHP in relation of expert's ponderation and in relation to initial weights obtained from neural network in order to minimize the subjectivity of the analysis process.

Keywords: Artificial Neural Networks, Fuzzy AHP, Environmental Vulnerability

\section{Introdução}

A análise de vulnerabilidade ambiental, frente a ocupação humana em bacias hidrográficas, envolve a consideração de diversos critérios. Os riscos naturais têm suas consequências danosas agravadas devido, sobretudo, à ocupação irregular de áreas que apresentam uma dinâmica natural intensa e a precariedade de organização espacial, contribuindo para a vulnerabilidade ambiental local. O esclarecimento deste tipo de cenários de análise tem especial importância para a busca de soluções, tornando-se relevante a adaptação de métodos e estratégias de estudos sobre planejamento de unidades urbanas que demonstrem aspectos com maior coerência para a preservação, proteção e conservação das unidades de paisagem (Guerra, 1980).

Durante o processo de decisão, grandes volumes de conjuntos de dados devem ser tratados e analisados (Tsiko e Haile, 2011). Considerando que a maior parte destes dados é intrinsecamente de natureza espacial, os Sistemas de Informação Geográfica (SIG) se apresentam como ferramentas para fornecer um quadro que integre a informação de forma consistente e permita a comunicação de cenários de vulnerabilidade para apoiar o pesquisador ou analista na determinação da vulnerabilidade a ocupações antrópicas. As decisões relacionadas com a gestão dos recursos ambientais são normalmente guiadas por diferentes grupos de decididores com interesses divergentes, que podem envolver questões técnicas, econômicas, ambientais ou sociais (Tsiko e Haile, 2011).

Nesse contexto, a determinação do grau de vulnerabilidade à ocupação antrópica de uma bacia hidrográfica pode ser realizada através de análises quantitativas, realizadas de forma semiautomática, em uma estrutura matemática, que permite descrever e sistematizar a análise de fatores ambientais e antrópicos de forma estruturada e lógica. Isto é realizado através de análises multicriteriais em ambiente SIG, com a ponderação das diversas camadas de informações. Existem diferentes técnicas para se chegar a ponderações que representem de forma adequada as questões técnicas, econômicas e ambientais envolvidas. Uma das técnicas para realizar essas ponderações é a Analytical Hierarchic Ponderation (AHP).

A AHP é uma técnica que surgiu como uma ferramenta de tomada de decisões para o gerenciamento empresarial (SAATY, 1990). Esta técnica tem sido utilizada nos mais diversos contextos que consideram dados espaciais, como em estudos de vulnerabilidade ambiental (Aher et al., 2013; Cereda Junior e Röhm, 2014), para estudo de fragilidade de solos (Donha et al, 2006; Wiegand et al, 2009), prospecção de minério (Cunha et al. 2001), seleção de área para disposição de resíduos (Hair et al. 2005), seleção de áreas para reservatórios (Tsiko e Haile, 
2011) e risco de movimento de massas geológicas suscetíveis a escorregamento (Komac, 2005; Santos e Sobreira, 2008; Vahidnia et al .2010).

O princípio da AHP é desmembrar um problema complexo em problemas menores e suas partes constituintes e, em seguida, orientar especialistas e tomadores de decisão a expressar a importância relativa de cada um dos elementos na hierarquia construída. Estes julgamentos são traduzidos em números, que são referidos como os pesos. A premissa desta técnica é a avaliação das ponderações de especialistas sobre determinado tema, comparando todos os fatores ou elementos de forma pareada. Este pareamento passa por uma normalização e combinações de forma que o resultado é um vetor de valores que mensuram a importância relativa de cada fator analisado em relação aos demais. Entretanto, a AHP apresenta algumas incertezas no processo de análise por não considerar o caráter subjetivo inerente às avaliações dos especialistas humanos nas ponderações iniciais, o que é comum em técnicas supervisionadas. Esta técnica somente avalia a consistência da matriz de valores pareados do sistema sem realizar qualquer avaliação de ruídos presentes nos valores de iniciais apresentados.

O problema elaborado para esta pesquisa é a identificação de uma forma de minimizar a subjetividade na obtenção de pesos aplicada na análise de vulnerabilidade ambiental. Portanto, parte-se da hipótese de que técnicas como as Redes Neurais Artificiais (RNA), podem contribuir no estabelecimento de parâmetros refinados na ponderação da matriz dominante da AHP como forma de minimizar a subjetividade desta técnica. A seleção das RNAs como proposta de solução é devido a sua capacidade de inferir padrões a partir de uma base de referência, com isso minimizando os ruídos de cada camada inserida. Esta hipótese se diferencia dos trabalhos de Akbari et al (2008), Vahidnia et al (2010), Tsiko e Haile (2011) e Aher et al (2013), que partem da abordagem de usar uma Função Fuzzy Triangular (TFN) dentro da matriz dominante da AHP para avaliar as variações nas ponderações iniciais realizadas. A mudança se dá em usar as RNAs na filtragem anterior à AHP, avaliando as ponderações individuais de cada especialista consultado.

Esta pesquisa propõe a avaliação da aplicação de RNA na compilação das ponderações iniciais de um conjunto de especialistas sobre as informações espaciais comumente utilizadas nas análises de vulnerabilidade ambiental em bacias hidrográficas na tentativa de estabelecer os pesos para cada uma dessas camadas em SIG. Para tanto foram propostas duas situações de teste. A primeira, chamada de caso 1, foi criada uma rede neural para compilar as ponderações por camada de informação, chamada de fator, considerada na análise e a segunda situação, caso 2, foi realizado um refinamento do primeiro caso, pois a rede foi utilizada para agregar as diferentes matrizes dominantes da AHP produzidas por cada especialista consultado. Ambos os casos de teste resultaram em um vetor de ponderação refinado obtido a partir dos dados de entrada da AHP.

\section{Analytic Hierarchy Process (AHP)}

A avaliação multicritério fornece um conjunto de técnicas e procedimentos para estruturar os problemas de decisão e projetar, avaliando e priorizando as alternativas no processo decisório (Malczewski, 2006). Ruhoff et al. (2004), constataram em seus estudos a existência de inúmeras técnicas que dão suporte a tomada de decisões. Dentre estas técnicas destaca-se a Analytic Hierarchy Process (AHP), que ajuda a organizar e estabelecer um modelo racional de combinação de dados e tem amplo uso na avaliação multicriterial. 
O método AHP foi desenvolvido por Satty $(1980 ; 1994)$ e trata-se de um método para a hierarquização de múltiplos critérios representativos de um problema organizados, em níveis de abstração ou detalhamento. A comparação pareada entre os fatores, ou critérios, é utilizada para determinar a importância relativa de cada fator, em que o especialista expressa sua opinião sobre o valor em uma comparação entre um par de dados. Por esta razão os critérios de entrada do método são representados na forma de matriz, chamada de matriz dominante, na qual as linhas e colunas recebem os valores relativizados pelos especialistas (Tabela 1). Em cada cruzamento de linhas e colunas da matriz o especialista atribui um valor relativo entre 1 (igual importância) a 9 (importância absoluta). Dessa forma, na parte triangular inferior o elemento recebe uma ponderação direta e, no lado oposto, o elemento da matriz é o inverso da ponderação do mesmo par. A diagonal principal da matriz é unitária (Tabela 1). Estas regras caracterizam que a matriz de decisão é sempre uma matriz quadrada, recíproca e positiva.

Tabela 1: Matriz de comparação pareada ou matriz dominante. Fonte: Baseado em Saaty (1990)

\begin{tabular}{c|cccc}
\hline Fatores & Fator 1 & Fator 2 & Fator 3 & Fator 4 \\
\hline Fator 1 & 1 & $1 / \mathrm{P} 2$ & $1 / \mathrm{P} 3$ & $1 / \mathrm{P} 4$ \\
Fator 2 & P2 & 1 & $1 / \mathrm{P} 2$ & $1 / \mathrm{P} 3$ \\
Fator 3 & P3 & P2 & 1 & $1 / \mathrm{P} 2$ \\
Fator 4 & P4 & P3 & P2 & 1 \\
\hline
\end{tabular}

Após a obtenção dos valores pareados $(\mathrm{P})$ entre os pares de fatores, divide-se cada elemento da coluna pela somatória da coluna a que pertence (Tabela 2). A média aritmética dos valores obtidos em cada linha, apresentadas na coluna à direita, representa os pesos normalizados $\left(\mathrm{P}_{n}\right)$. Estes pesos são o que Saaty (1994) chama de prioridade do parâmetro, ou seja, o peso inicial deste parâmetro na análise. O resultado desta etapa é um autovetor onde cada valor apresentado na coluna Pesos representa uma ponderação a ser atribuído na criação do mapa em SIG. Este autovetor é normalizado, ou seja, os pesos variam de 0 a 1 , sendo que a somatória de todo os pesos calculados é 1 .

Tabela 2: Caso genérico para determinação dos pesos. Fonte: Autores

\begin{tabular}{|c|c|c|c|c|c|}
\hline Fatores & Fator 1 & Fator 2 & Fator 3 & Fator 4 & Pesos \\
\hline Fator 1 & F1/ $/$ Coluna1 & F1/ $/ \sum$ Coluna 2 & F1/ $/$ Coluna3 & F1/ $/$ Coluna 4 & $\sum_{\text {Linhal }} / \mathrm{n}$ \\
\hline Fator 2 & $\mathrm{~F} 2 / \Sigma$ Coluna 1 & $\mathrm{~F} 2 / \Sigma$ Coluna 2 & $\mathrm{~F} 2 / \Sigma$ Coluna 3 & $\mathrm{~F} 2 / \Sigma$ Coluna 4 & $\sum_{\text {Linha } 2} / n$ \\
\hline Fator 3 & $\mathrm{~F} 3 / \sum$ Coluna 1 & $\mathrm{~F} 3 / \Sigma$ Coluna 2 & $\mathrm{~F} 3 / \Sigma$ Coluna 3 & $\mathrm{~F} 3 / \sum$ Coluna 4 & $\sum_{\text {Linha3 }} / n$ \\
\hline Fator 4 & $\mathrm{~F} 4 / \Sigma$ Coluna 1 & $\mathrm{~F} 4 / \sum$ Coluna 2 & $\mathrm{~F} 4 / \sum$ Coluna 3 & $\mathrm{~F} 4 / \sum$ Coluna 4 & $\sum_{\text {Linha }} / \mathrm{n}$ \\
\hline $\begin{array}{l}\text { Somatório } \\
\text { das colunas }\end{array}$ & $\sum_{\text {Columal }}$ & $\sum_{\text {Coluna2 }}$ & $\sum_{\text {coluna3 }}$ & $\sum_{\text {Coluna4 }}$ & $\sum_{\text {pasos }}=1$ \\
\hline
\end{tabular}

Triantaphyllou e Mann (1995) destacam que quando muitas comparações de pares são realizadas, algumas inconsistências podem surgir e não há garantia de que a matriz dominante seja recíproca positiva e consistente. Por isso, é necessário examinar a consistência da matriz através de um índice de consistência (IC). Este índice é calculado através de uma aproximação do autovalor dos pesos obtidos $\left(\lambda_{\max }\right)$ e o número de fatores, ou informações, utilizadas por meio da fórmula (Equação 1): 


$$
\mathrm{IC}=\frac{\left(\lambda_{\max }-\mathrm{n}\right)}{(\mathrm{n}-1)}
$$

Onde, $\mathrm{n}$ é o número de fatores usados (número de colunas ou linhas) e $\lambda$ max é o autovalor que é obtido a partir do resultados da análise da matriz dominante.

Dividindo-se o valor IC pelo índice aleatório IR criado por Saaty (1994), apresentado na Tabela 3, obtém-se um novo índice chamado de razão de consistência (CR). Valores de CR acima de 0,10 indicam que os julgamentos podem ser não confiáveis e é preciso se reavaliar o entendimento e estruturação do problema para uma nova ponderação (Triantaphyllou e Mann, 1995).

Tabela 3: Valores de IR para matrizes de ordem n. FONTE: Adaptado de Triantaphyllou e Mann (1995)

\begin{tabular}{c|c|c|c|c|c|c}
\hline Ordem da matriz (n) & $\mathbf{2}$ & $\mathbf{3}$ & $\mathbf{4}$ & $\mathbf{5}$ & $\mathbf{6}$ & $\mathbf{7}$ \\
\hline Indice aleatório (IR) & 0,0 & 0,58 & 0,90 & 1,12 & 1,24 & 1,32 \\
\hline
\end{tabular}

Entendendo que o CR é uma inconsistência na técnica AHP, pois pode ocultar erros significantes devido a estruturação da análise do problema, as ponderações iniciais e a aleatoriedade do índice, essa pesquisa aplicou as Redes Neurais Artificiais no refinamento das ponderações de entrada na etapa de treinamento da rede.

Experiências como Akbari et al (2008), Vahidnia et al (2010), Tsiko e Haile (2011) e Aher et al (2013) partem da mesma abordagem em estabelecer as ponderações inicias da matriz dominante como uma função fuzzy triangular (TFN). Nesta função, a ponderação inicial é indicada juntamente com os limites possíveis dos valores do fator analisado em uma tríade numérica, como por exemplo a ponderação de um fator genérico $\mathrm{F}=\{1,2 ; 3 ; 4,5\}$. Entretanto nestas pesquisas, após os TFN calculados, o desenvolvimento da AHP é convencional sem a aplicação das redes neurais propriamente.

Portanto, a intenção desta pesquisa para definição da ponderação das camadas de informação do SIG, chamados de fatores na AHP, é aplicar uma rede neural antes da criação da matriz dominante da AHP. Em outras palavras, as RNAs serão utilizadas para agregar os dados dos especialistas e realizar uma filtragem inicial dos dados que comporão a matriz dominante na AHP. Esta abordagem difere dos autores supracitados ao propor a ponderação com um único valor refinado para o pareamento dos fatores. Dessa forma, esta metodologia consegue integrar SIG, RNA e a AHP convencional para modelar a vulnerabilidade ambiental em SIG através de um conjunto específico de informações espaciais.

\section{Materiais e Métodos}

\section{1 Área de Estudo}

A área definida para o estudo é a bacia do Córrego do Fundo no município de Carmo do Paranaíba, Triângulo Mineiro, oeste do Estado de Minas Gerais, Brasil. O mapa de localização é apresentado na Figura 1. O clima da região é classificado como Aw com pluviosidade média anual de $1470 \mathrm{~mm}$ (Felfili et al., 1999). As temperaturas médias anuais são de $20,4^{\circ} \mathrm{C}$, com 
máximas de $28,5^{\circ} \mathrm{C}$ e mínimas de $12^{\circ} \mathrm{C}$. De acordo com o IBGE (2012), o município possui uma população de 29.752 habitantes, e a bacia do Córrego do Fundo detém em seu interior importantes pontos de captação do sistema de abastecimento da cidade. Esta bacia, entretanto, sofre com a gradual passagem de uma ocupação agrícola para área urbana.

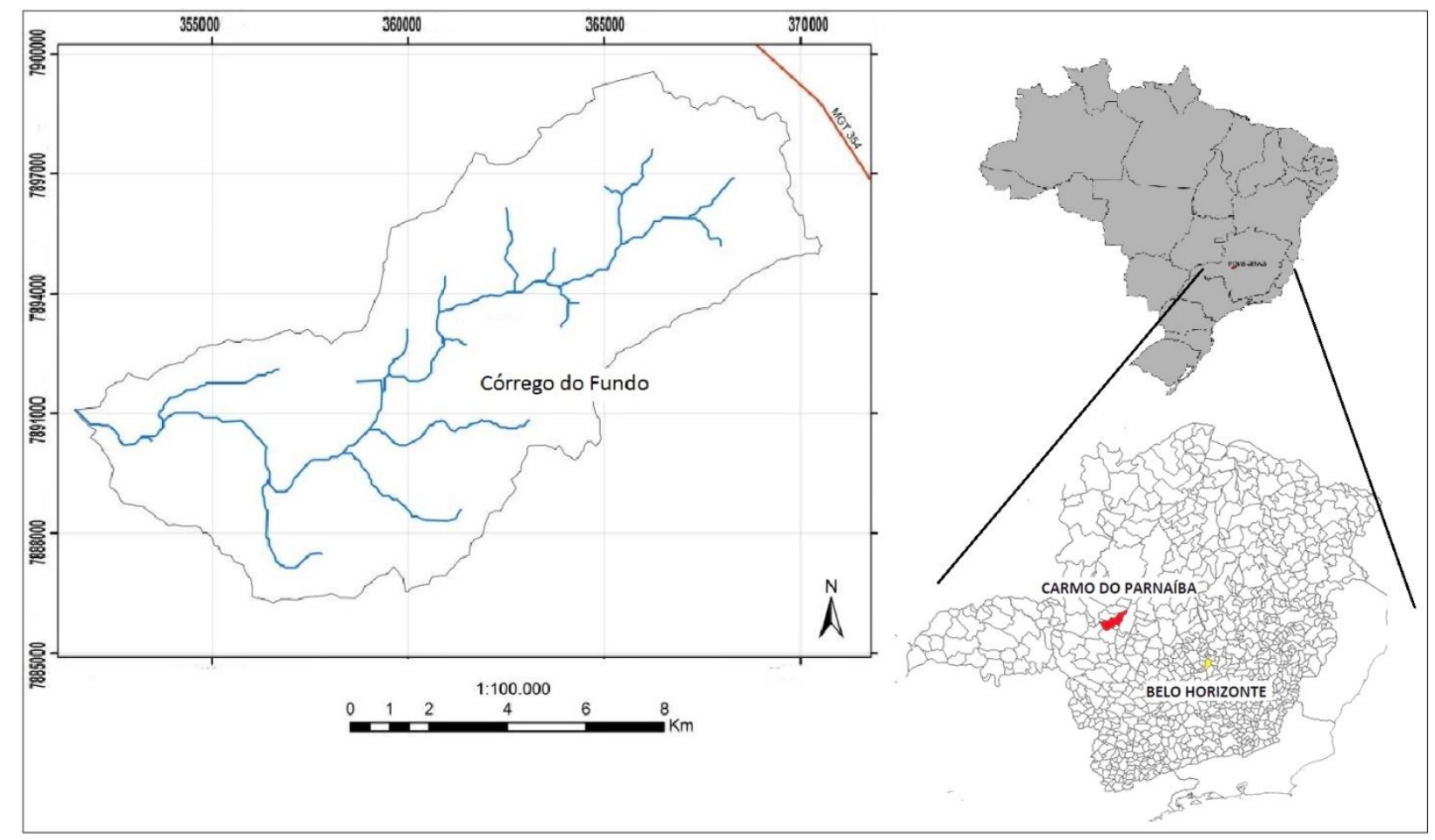

Figura 1: Figura com a localização da área de estudo.

Fonte: Autores

\subsection{Dados utilizados}

A literatura apresenta uma grande variedade de informações utilizadas no estudo de vulnerabilidade ambiental. De acordo com Wang et al (2008), o número de informações pode variar consideravelmente, chegando a mais de 15 camadas diferentes. Por isso, para esta pesquisa foram selecionadas informações espaciais comumente utilizadas nas análises de vulnerabilidade ambiental em bacias hidrográficas, que são a declividade, a pedologia, a pluviometria e uso e ocupação do solo. Estas informações são apresentadas no trabalho de Ross (1994) que tem sido utilizado em outras pesquisas, principalmente no Brasil, como Dias e Silva (2014), Souza et al. (2011), Wiegand et al (2009), Santos e Sobreira (2008), Silveira e Oka-Fiori (2007).

Os dados altimétricos da Bacia do córrego do Fundo foram obtidos a partir do projeto Topodata (Instituto Nacional de Pesquisas Espaciais - INPE, 2014) elaborados a partir dos dados SRTM disponibilizados pelo USGS. A escala destes dados é 1:75.000. O Modelo Digital do Terreno (MDT) foi trabalhado no ArcGis e foi elaborado um mapa de declividade. As classes definidas foram baseadas no trabalho de Ross (1994), que apresenta os valores limites de até 6\%, de 6 a $12 \%$, de 12 a $20 \%$, de 20 a $30 \%$ e acima de $30 \%$, respectivamente, Plano, Suave Ondulado, Ondulado, Forte Ondulado e Montanhoso. Os dados referentes aos tipos de solo da área estudada 
foram obtidos de uma base de dados da Empresa Brasileira de Pesquisas Agropecuárias (EMBRAPA, 1999). O mapa de pluviometria foi elaborado em ArcGis de acordo com os levantamentos históricos meteorológicos sobre as chuvas dos últimos 30 anos disponíveis no banco de dados da Agência Nacional de Águas (ANA, 2014), disponíveis no sitio da agência, e interpolados com uso do método de interpolação do Inverso da Distância Ponderada (IDW), disponível no ArcGis. O mapa temático de uso e ocupação do solo foi realizado a partir classificação supervisionada pelo método de classificação da Máxima Verossimilhança da imagem do satélite Spot 4 com resolução espacial de cinco metros. As cinco classes de uso e ocupação adotadas foram baseadas no trabalho de Ross (1994) e são solo exposto, água, vegetação nativa, pasto e culturas. O índice kappa obtido da classificação ficou acima de $91 \%$. Após a preparação individual, todas as camadas de informação foram compatibilizadas para a escala menos detalhada, ou seja, cada camada teve sua escala degradada para 1:75.000.

\subsection{Metodologia aplicada}

A metodologia está dividida em duas etapas. Na primeira elaborou-se o mapa de vulnerabilidade através da AHP da forma convencional, ou seja, da forma como vem sendo empregada nos estudos relatados e usá-la como padrão de comparação. Nela foram adotadas as classes de vulnerabilidade e uso do solo conforme Ross (1994). Estes valores diferem em número de classes e limiares, por exemplo na declividade em relação a EMBRAPA (1999), mas tem sido adotado em trabalhos de vulnerabilidade ambiental. Os valores considerados estão apresentados na Tabela 4.

Tabela 4: Escalas de Vulnerabilidade Proposta por Ross (1994) considerando os dados utilizados na pesquisa. Fonte: Autores (2015)

\begin{tabular}{c|c|cccc}
\hline $\begin{array}{c}\text { Peso } \\
\text { Atribuído }\end{array}$ & $\begin{array}{c}\text { Classes de } \\
\text { Vulnerabilidade }\end{array}$ & $\begin{array}{c}\text { Declividade } \\
\mathbf{( \% )}\end{array}$ & Tipos de Solo & Uso do Solo & $\begin{array}{c}\text { Pluviometria } \\
\text { (mm) }\end{array}$ \\
\hline 1 & Muito fraca & Até 6\% & Latossolo Verm. Escuro & Mata Nativa & $1300-1360$ \\
2 & Fraca & $6-12 \%$ & Latossolo UMA & Culturas & $1361-1420$ \\
3 & Média & $12-20 \%$ & Cambissolo & Água & $1421-1479$ \\
4 & Forte & $20-30 \%$ & - & Pastagem & $1480-1535$ \\
5 & Muito Forte & $>30 \%$ & - & Solo Exposto & $1536-1600$ \\
\hline
\end{tabular}

A segunda etapa foi realizada através de dois casos de aplicação de RNA diferentes. O caso 1 foi realizado através da solicitação a um grupo de cinco especialistas em recursos hídricos, com formação em engenharia civil, agronomia e geografia e sem conhecimento prévio da região, que indicassem em um questionário a ponderação de cada elemento pareado com os demais. $\mathrm{O}$ questionário apresentou perguntas sobre a avaliação pareada da importância de cada fator, conforme a técnica AHP, que deveriam ser respondidas em uma escala de 1 a 9 . A rede foi utilizada para agregar as diferentes ponderações por fatores, ou seja, cada camada de informação espacial foi avaliada separadamente para compor uma única matriz dominante como parâmetro de entrada na AHP.

O caso 2 foi um refinamento do caso 1, no qual foi utilizado uma rede neural para agregar as diferentes matrizes dominantes obtidas a partir das considerações dos especialistas. Em outras palavras, foi criada uma única matriz representativa como matriz dominante da AHP a partir das cinco matrizes elaboradas por cada especialista. Os resultados dos questionários foram processados, e como resultado, foram gerados cinco autovetores de ponderação. Esses 
autovetores serviram de dados de treinamento para a RNA criada. Isto pode ser entendido como um refinamento dos dados ou como uma nova amostragem sobre os dados dos especialistas de acordo com Yamamoto e Lamdim (2013). Esta alternativa representa uma segunda amostragem mais suavizada e, portanto, com maior potencial de minimização da subjetividade maior.

As redes neurais multicamadas com o algoritmo backpropagation foram criadas através da rotina NNTOOL do Matlab. Essas rotinas permitem a configuração da rede e variação das funções de ativação em várias passagens de forma a ajustar de forma interativas pesos entre os neurônios de cada camada. Baseado no trabalho de Spörl (2000), foram avaliadas redes em combinação de número de camadas e neurônios por camadas em relação ao número de parâmetros. Spörl (2000) afirma que o número de camadas e neurônios deve ser explorado entre o mínimo de dois e o máximo igual ao número de fatores avaliados. Em outras palavras, o número de camadas avaliadas variou de 2 a 4 camadas, sendo que em cada configuração variou-se o número de neurônios nas camadas intermediárias entre 2 e 4 neurônios. Dentre as opções analisadas em préteste das redes, a que apresentou melhores ajustes às funções, avaliadas a dispersão das amostras, foi a de quatro neurônios e quatro camadas intermediárias. Além disso, foram variadas as funções de ativação considerando tangente hiperbólica, a degrau e a sigmoidal.

Para o treinamento foi utilizada a função trainlm. Esta função atualiza os valores de peso e de ruídos de acordo com a otimização de Levenberg-Marquardt, com as ponderações da AHP de 1 a 9 normalizados entre 0 e 1 para os dados de treinamento. Esta função usa o jacobiano da matriz de entrada para os cálculos, o que pressupõe que o desempenho é a soma dos quadrados dos erros. Portanto, redes treinadas com esta função devem usar o erro médio quadrático (EMQ) como função de parada (Matworks, 2015). Esta função é o algoritmo backpropagation com menor tempo de processamento disponível no Matlab, e é altamente recomendado como primeira escolha ao selecionar algoritmos supervisionados, apesar de exigir mais memória do que outros algoritmos (Matworks, 2015). A função de aprendizagem foi a learngdm que avalia a redução do gradiente dos pesos de cada neurônio de maneira dinâmica e os ruídos envolvidos. A função calcula a mudança de peso para um determinado neurônio de entrada, a taxa de aprendizado e o momento constante.

\section{Resultados e Discussões}

Os valores das ponderações da AHP calculada a partir das ponderações dos especialistas estão apresentados na Tabela 5.

Tabela 5: Autovetor de ponderação AHP Fonte: Autores

\begin{tabular}{c|cccc}
\hline Pesos & Precipitação & Tipo de Solo & Uso do Solo & Declividade \\
\hline Pesos AHP & 0,0569 & 0,1219 & 0,2633 & 0,5579 \\
\hline
\end{tabular}

Considerando a escala de 0,90 de valores IR para matrizes de ordem n (Tabela 3), chega-se ao RC de 0,032441. Sendo este valor é menor de 0,1 (10\%), procede-se o cálculo do índice de consistência (IC) resultando em um valor de 0,02920.

Ao realizar uma avaliação das áreas encontradas no mapa de vulnerabilidade gerado a partir dos pesos indicados na Tabela 4, foram encontrados $24,87 \%$ da área na classe muito fraca, 40,33\% na classe fraca, $21,49 \%$ na classe média e $9,77 \%$ e $3,54 \%$, respectivamente às classes de 
vulnerabilidade forte e muito forte. Esses percentuais indicam que apenas 15,04 ha (13,39\%) da bacia do Córrego do Fundo se encontram com índices de vulnerabilidade alta.

No teste com a primeira variação, chamado de caso 1, os especialistas responderam ao questionário indicando a avaliação dos fatores em pares. A partir das repostas foram calculados os pesos individuais conforme a AHP baseado nos valores sugeridos pelo especialista. O resultado de cada especialista está representado em cada linha numerada na Tabela 6.

Tabela 6: Ponderação obtida pela AHP a partir dos especialistas. Fonte: Autores

\begin{tabular}{c|cccc}
\hline Especialista & Precipitação & Tipo de Solo & Uso do Solo & Declividade \\
\hline 1 & 0,234 & 0,195 & 0,256 & 0,313 \\
2 & 0,101 & 0,199 & 0,317 & 0,381 \\
3 & 0,250 & 0,236 & 0,277 & 0,236 \\
4 & 0,222 & 0,224 & 0,277 & 0,275 \\
5 & 0,373 & 0,303 & 0,164 & 0,158 \\
\hline
\end{tabular}

Nota-se na Tabela que existe uma certa variação dos pesos calculados para cada fator. Em uma análise de correlação nessas ponderações encontrou-se que as correlações por fator ficaram acima de 0,9871 e as respectivas covariâncias abaixo de 0,0018. Isto indica que os especialistas mesmo de áreas de formação diferente observam os fatores de forma semelhante em uma análise de vulnerabilidade ambiental. Os pesos dos especialistas foram submetidos à rede composta por quatro camadas intermediárias e quatro neurônios, e foram utilizadas três funções de ativação da rede (Tabela 7).

Tabela 7: Resultado da RNA do Caso 1 a partir dos especialistas. Fonte: Autores

\begin{tabular}{c|cc|cc|cc}
\hline Classe & $\begin{array}{c}\text { Pesos } \\
\text { Tangente } \\
\text { Hiperbólica }\end{array}$ & Erro & $\begin{array}{c}\text { Pesos } \\
\text { Degrau }\end{array}$ & Erro & $\begin{array}{c}\text { Pesos } \\
\text { Sigmoidal }\end{array}$ & Erro \\
\hline 1 & 0,10757 & $-0,05068$ & 0,49353 & $-0,43664$ & 0,065899 & $-0,0090089$ \\
2 & 0,48418 & $-0,36231$ & 0,5488 & $-0,42692$ & 0,1169 & 0,004975 \\
3 & 0,54796 & $-0,28462$ & 0,26335 & $9,92 \mathrm{E}-04$ & 0,2197 & 0,043648 \\
4 & 0,55789 & $9,13 \mathrm{E}-03$ & 0,55788 & $8,33 \mathrm{E}-02$ & 0,32463 & 0,23326 \\
\hline
\end{tabular}

A decisão de qual função utilizar baseou-se no coeficiente de correlação entre as séries de treinamento. Isto se justifica na premissa de que os coeficientes da rede são calibrados de forma a filtrar os ruídos, ou divergências, nas ponderações informadas. Os valores do coeficiente de correlação encontrado para a função tangente hiperbólica foi de $-0,41484$, para a função degrau foi de 0,92655 e para a sigmoidal foi de 0,73238 . Ao observar os resultados constatou-se que a função degrau obteve a correlação mais expressiva com os dados de entrada dos especialistas, sendo o vetor de pesos desta função utilizado para a elaboração da carta de vulnerabilidade ambiental do caso 1.

No caso 2, foi utilizado os dados ponderados no primeiro caso como dados de entrada da matriz dominante, obtendo-se os resultados apresentados na Tabela 8. Analisando a Tabela observa-se que a função de tangência hiperbólica não obteve correlação eficiente com os dados de entrada, já a função degrau atingiu uma correlação muito fraca. 
Tabela 8: Resultado da Rede (Caso 2), refinamento. Fonte: Autores

\begin{tabular}{c|cc|cc|cc}
\hline Classes & $\begin{array}{c}\text { Pesos } \\
\text { Tangente } \\
\text { Hiperbólica }\end{array}$ & Erro & $\begin{array}{c}\text { Pesos } \\
\text { Degrau }\end{array}$ & Erro & $\begin{array}{c}\text { Pesos } \\
\text { Sigmoidal }\end{array}$ & Erro \\
\hline 1 & 0,16665 & $-0,10076$ & 0,1356 & $-0,021732$ & 0,087631 & $-0,069703$ \\
2 & 0,12701 & $-0,010106$ & 0,070181 & 0,002695 & 0,11421 & 0,046719 \\
3 & 0,22649 & $-0,006786$ & 0,072063 & $-0,048017$ & 0,26772 & 0,14764 \\
4 & 0,21344 & 0,11119 & 0,16655 & 0,014457 & 0,31017 & 0,15808 \\
\hline
\end{tabular}

Os resultados apontam que a função sigmoidal obteve uma melhor correlação $\left(R^{2}=0,82682\right)$ do que a função Degrau $\left(\mathrm{R}^{2}=0,11271\right)$, e a função tangente hiperbólica teve pouca variação no valor em relação ao caso anterior. Sendo assim foi utilizado os valores obtidos com essa rede para a elaboração da carta de vulnerabilidade ambiental.

Ao realizar a avaliação das áreas encontradas no mapa de vulnerabilidade gerado a partir dos pesos pelos especialistas, foram encontradas variações em relação a AHP. Foram encontrados os valores de 18,25\% da área na classe muito fraca, 34,99\% na classe fraca, 25,00\% na classe média, $16,66 \%$ na classe forte e $5,10 \%$ na classe muito forte. Estes valores alteram as áreas com altos valores de vulnerabilidades de 13,39\% obtido na AHP para 21,76\%. Os mapas resultantes são apresentados na Figura 2.

$\mathrm{Na}$ figura são indicadas as áreas que sofreram maiores modificações em relação a técnica AHP, sendo denominadas por $1 \mathrm{~A}$ e $1 \mathrm{~B}$, as áreas na técnica AHP; $2 \mathrm{~A}$ e $2 \mathrm{~B}$ as áreas do caso 1, com avaliação dos especialistas por fator, e; $3 \mathrm{~A}$ e $3 \mathrm{~B}$ as áreas do caso 2, com a avaliação pela agregação das matrizes dominantes.

Analisando-se a Figura 2 e a Tabela 9, observa-se que a classe Muito Fraca apresentou uma variação entre o cenário do AHP e o Caso 1 com redução da área 24,87\% para 18,25\%. Esta classe teve um pequeno acréscimo de área no Caso 2, passando para 26,15\%. Ao analisar a classe Fraca, observa-se que houve uma redução acentuada de área entre os cenários, passando de $40,33 \%$ na AHP para 34,99\% no Caso 1 e para $27,48 \%$ no Caso 2, demonstrando um decrescimento total de $12,69 \%$ ou 14,81 hectares. A classe de vulnerabilidade Média apresentou primeiramente um acréscimo de área, de $21,49 \%$ no cenário AHP para $25 \%$ no cenário do Caso 1 , e posteriormente este valor retornou a $21,46 \%$ no cenário do Caso 2. As classes Fortes e Muito Forte apresentaram um comportamento de acréscimo de área. Na AHP, a classe Forte representa 9,77\% da área da bacia, no Caso 1 passa para 16,66\% e no cenário do Caso 2 para 17,66\%. Por fim, a classe Muito Forte iniciou no cenário AHP com 3,54\% passando para 5,09\% no cenário do Caso 1 e 7,24\% no cenário do Caso 2. 


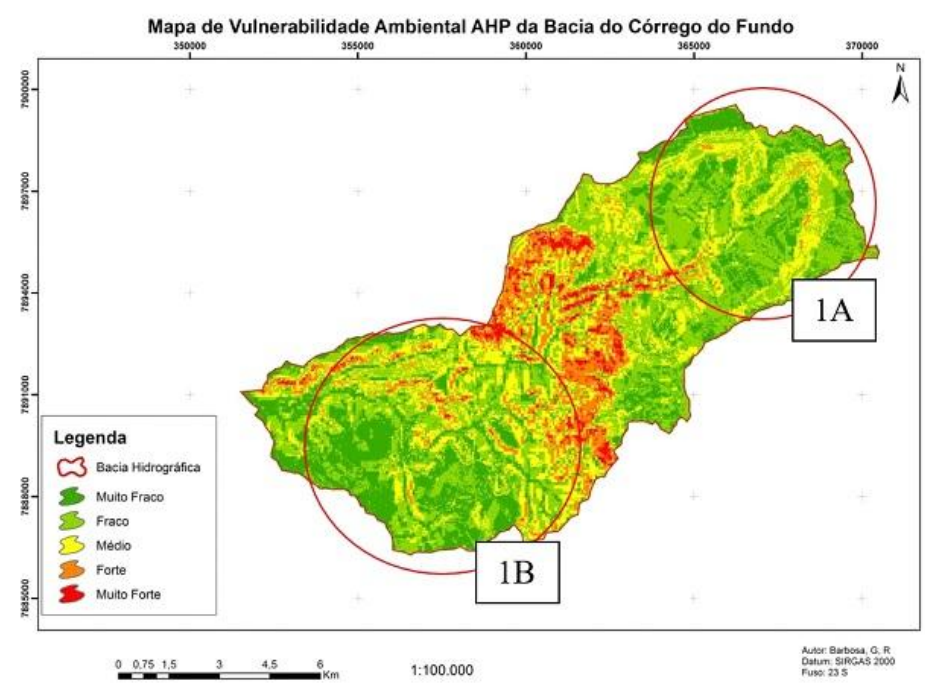

a)

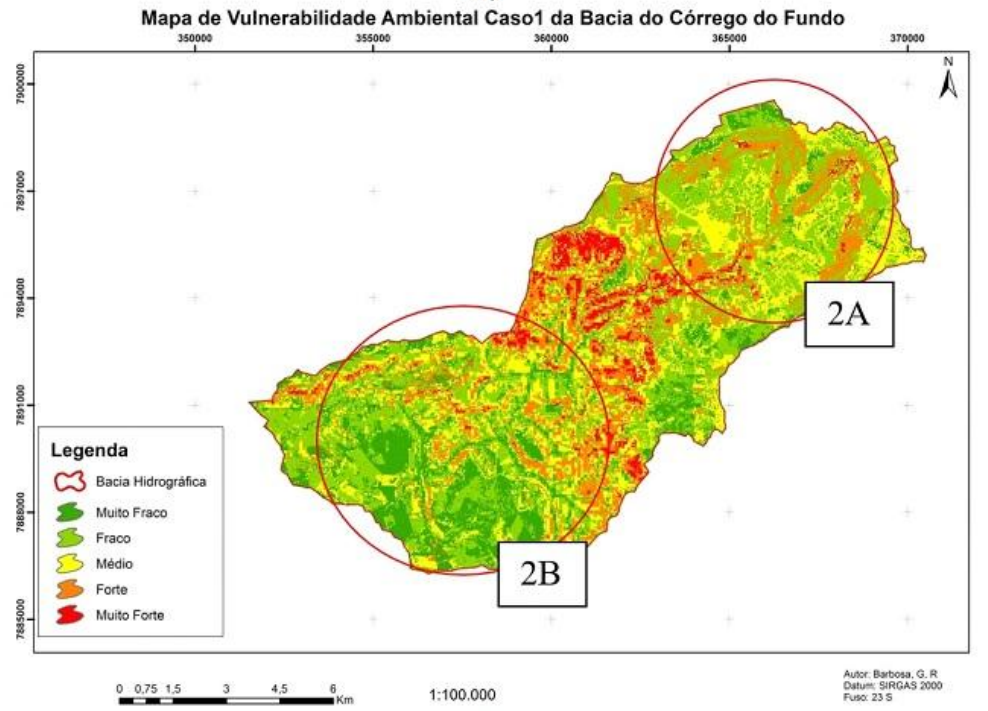

b)

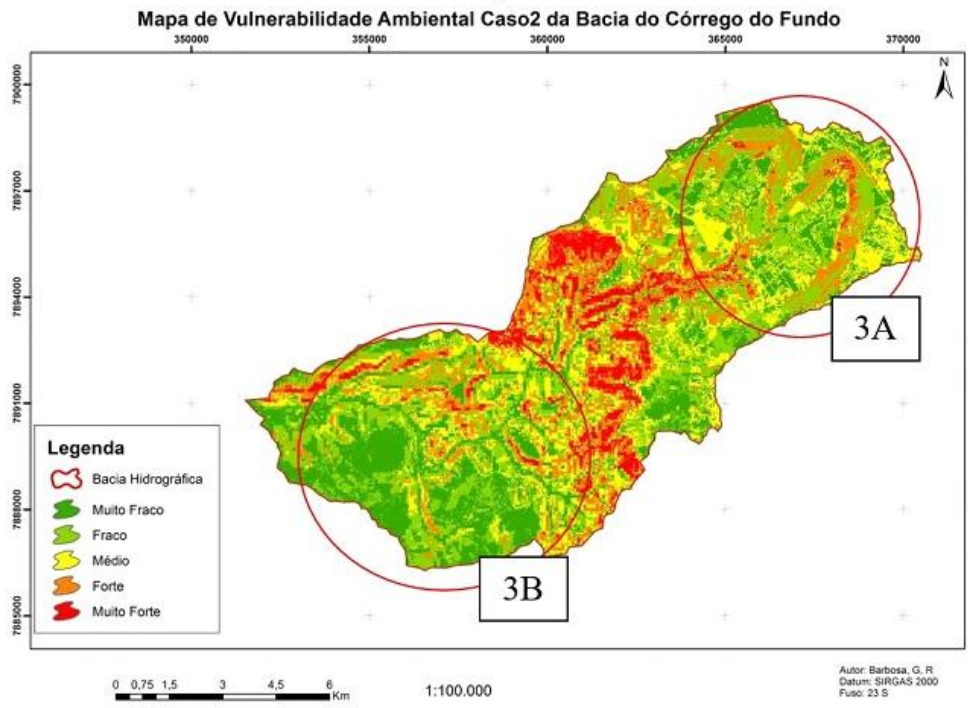

c)

Figura 2: Imagens dos mapas produzidos com as ponderações a) AHP, b) Caso 1 e c) Caso 2 Fonte: Autores 
Tabela 9: Área e Percentual Variação AHP, Caso 1 e Caso 2. Fonte: Autores

\begin{tabular}{c|cc|cc|cc}
\hline \multirow{2}{*}{$\begin{array}{c}\text { Classes de } \\
\text { vulnerabilidade }\end{array}$} & \multicolumn{2}{|c|}{ AHP (\%) } & \multicolumn{2}{c|}{ Caso l (Rede l) } & \multicolumn{2}{c}{ Caso 2 (Rede 2) } \\
\cline { 2 - 7 } & Área km $\mathbf{~ k r}^{\mathbf{2}}$ & $\%$ & Área $\mathbf{k m}^{\mathbf{2}}$ & $\%$ & Área $\mathbf{k m}^{\mathbf{2}}$ & $\%$ \\
\hline Muito Fraca & 28,12 & 24,87 & 20,44 & 18,25 & 29,29 & 26,15 \\
Fraca & 45,59 & 40,33 & 39,19 & 34,99 & 30,78 & 27,48 \\
Média & 24,30 & 21,49 & 28,00 & 25,00 & 24,04 & 21,46 \\
Forte & 11,04 & 9,77 & 18,66 & 16,66 & 19,78 & 17,66 \\
Muito Forte & 4,00 & 3,54 & 5,71 & 5,10 & 8,11 & 7,24 \\
\hline Total & 113,05 & 100 & 113,05 & 100 & 113,05 & 100 \\
\hline
\end{tabular}

A Figura 3 apresenta um gráfico com as variações de cada classe em relação ao todo. Percebe-se que a AHP concentra a maior parte da área da bacia nas classes mais baixas de vulnerabilidade enquanto a distribuição de área entre os casos 1 e 2 tem uma distribuição de área mais próximas.

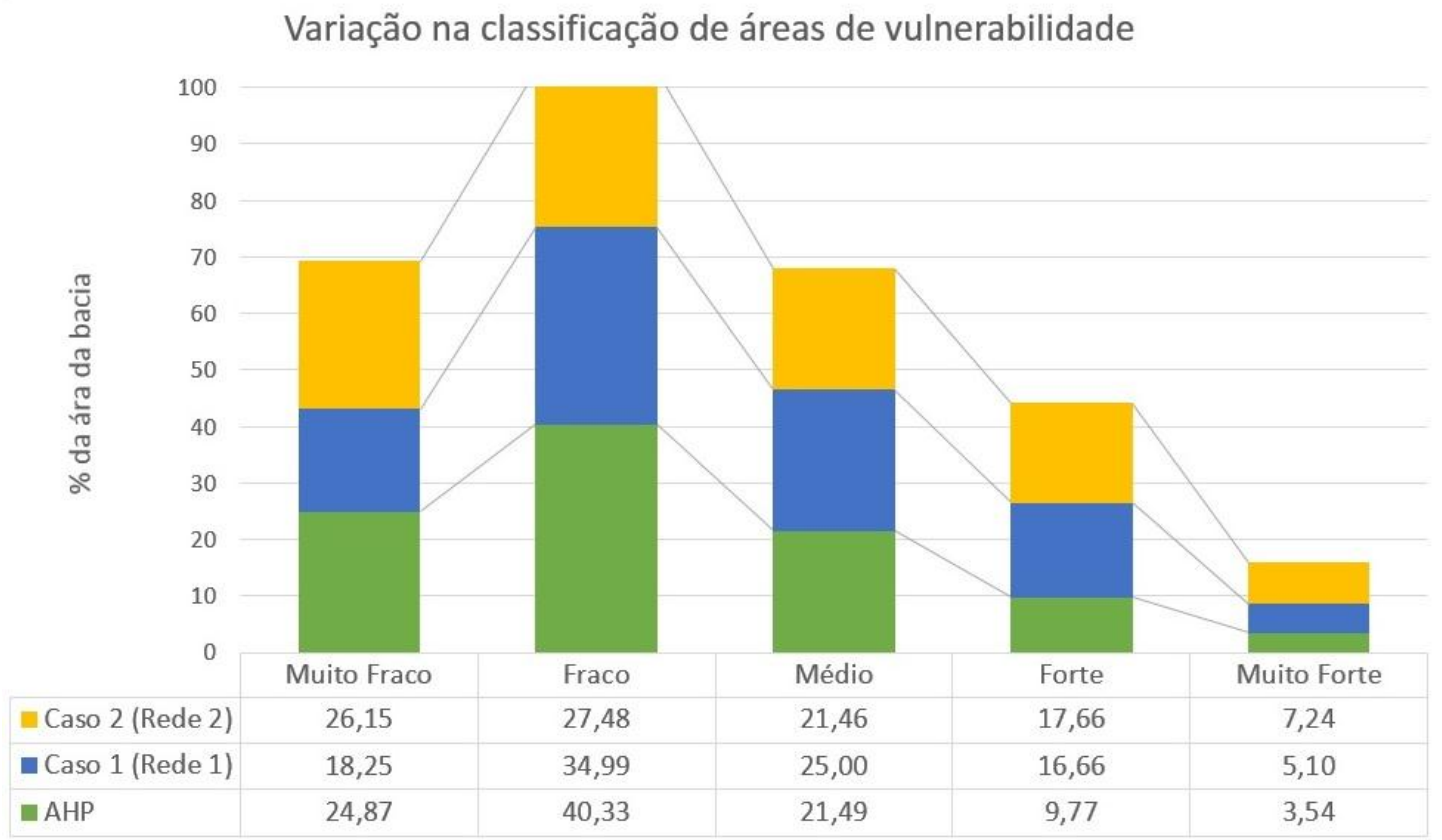

Figura 3: Gráfico da Comparação de áreas obtidas nas comparações Fonte: Autores

\section{Conclusões}

A modelagem da vulnerabilidade ambiental é um grande desafio, pois implica em entender de forma qualitativa e quantitativa a relação entre diversas variáveis ambientais e a dinâmica natural das mesmas, que é extremamente complexa. Apesar da dificuldade em expressar a dinâmica natural em modelos matemáticos, o método AHP apresenta certo grau de acerto, mesmo sob a 
consideração de que a técnica é limitada na sua avaliação da qualidade da ponderação. Umas dessas limitações está representada na relação da subjetividade dos dados de entrada e da avaliação da matriz pareada pela razão de consistência (CR), que expressa um fator de coesão da matriz pareada.

Nesse contexto de incertezas, este estudo aplicou as redes neurais (RNA) através da ponderação realizada por especialistas, na tentativa de reduzir a subjetividade do processo para elaboração da representação da vulnerabilidade em SIG. A capacidade da RNA em lidar com um grande número de dados deixa condições vantajosas em relação aos modelos comumente utilizados para trabalhar dados ambientais, pois existe a possibilidade de envolver um número maior de fatores representativos do problema a serem considerados.

Ao observar os resultados obtidos nesta pesquisa é possível concluir que existe uma a aproximação dos valores obtidos nas avaliações com as RNAs por fator individualizado (Caso 1) e por matriz dominante (Caso 2). Enquanto na AHP, as ponderações tendem a considerar um dos fatores de análise preponderante em relação aos demais, em geral a declividade, os resultados obtidos com as RNAs permitem que diferentes variáveis sejam avaliadas de forma conjunta sem uma especial relevância na matriz dominante.

O resultado do Caso 1, apresentou uma variação das áreas entre classes aumentando os valores nas classes forte e muito forte em relação ao que foi encontrado na AHP. Os resultados da aplicação do Caso 2 com a utilização do refinamento apresentou maior distinção das classes com maior assertividade. Apesar da possível influência das experiências e formações dos especialistas face a diversidade das informações, observa-se o valor da correlação das respostas acima dos 98\%. Este valor é coincidente com aqueles obtidos pela rede com a função de ativação degrau, apesar do índice ter ficado entorno de $92 \%$. Considerando o tamanho do grupo, apenas cinco especialistas, e a diversidade da formação nesta especialidade de estudo, considera-se que a RNA tem potencial para sua aplicação no refinamento dos dados de entrada da técnica AHP. Concluindo as considerações dos cenários, foi possível identificar que a diferença existente entre os mapas pode ser esclarecida pelos ruídos existentes na técnica AHP, e a utilização das redes neurais artificiais juntamente com o refinamento do segundo caso, possibilitou certa redução da subjetividade das ponderações iniciais. Não foi possível associar uma função específica para cada caso e novas pesquisas são necessárias na tentativa de selecionar um grupo de funções para as diferentes abordagens.

Apesar da redução das subjetividades observou-se que as mesmas não foram totalmente extintas, indicando a necessidade de novos estudos. Concluindo essa pesquisa, um importante ponto para a sua continuação é desassociar as ponderações iniciais do paradigma da declividade como elemento principal, assim vinculando ao método novas ponderações para possuir dados mais assertivos para as análises ambientais.

\section{REFERÊNCIAS BIBLIOGRÁFICAS}

Aher P. D., Adinarayana, J., e Gorantiwar, S.D. "Prioritization of watersheds using multi-criteria evaluation through fuzzy analytical hierarchy process". Agric Eng Int: CIGR Journal. 15 (2013): 11-18.

Akbari, V.; Rajabi, M.A.; Chavoshi, S.H. e Shams, R. "Landfill Site Selection by Combining GIS and Fuzzy Multi Criteria Decision Analysis, Case Study: Bandar Abbas, Iran". World 
Applied Sciences Journal (Supple 1): (2008) 39-47. ISSN 1818-4952. IDOSI Publications, Tehran, Iran.

ANA. 2014. URL: http://www2.ana.gov.br/Paginas/servicos/informacoeshidrologicas/ redehidro.aspx

Cereda Junior, A. e Röhm, S.A. Analysis of environmental fragility using multi-criteria analysis (MCE) for integrated landscape assessment. Journal of Urban and Environmental Engineering. 8 (2014): 28-37. ISSN 1982-3932 doi: 10.4090/juee.2014.v8n1.028037

Cunha, R. C. da; Dupas, F. A.; Pons, N. A. D. e Tundisi, J. G.. "Análise da influência das variáveis ambientais utilizando inferência fuzzy e zoneamento das vulnerabilidades". Geociências. 30 (2011): 399-414. São Paulo, UNESP

Dias, V. S. B. e Silva, A. de B. da. "AHP na modelagem da vulnerabilidade ambiental do mini corredor ecológico serra das onças (BA)". Revista Brasileira de Cartografia. 66 (2014): 13631377. ISSN: $1808-0936$

Donha, A. G.; Souza, L. C. de P. e Sugamosto, M. L. "Determinação da fragilidade ambiental utilizando técnicas de suporte à decisão e SIG". Revista Brasileira de Engenharia Agrícola e Ambiental. 10 (2006): 175-181.

EMBRAPA. "Sistema Brasileiro de Classificação de Solos". Centro Nacional de Pesquisa de Solos. Brasília: Embrapa Produção de Informação, Rio de Janeiro. 1999

Felfili J.M., Junior M.C.S., Dias B.J. e Rezende A.V. "Estudo fenológico de Stryphnodendron adstringens (Mart.) Coville no cerrado sensu stricto da Fazenda Água Limpa no Distrito Federal, Brasil’. Rev. bras. Bot. 22 (1999). São Paulo Apr.

Guerra, A.T. Dicionário geológico e geomorfológico, Rio de Janeiro: IBGE, 1980. 446 p.

Hair, J.F.; Anderson, R.E.; Tatham, R.L.; Black, W. Análise Multivariada de dados. Porto Alegre. 5. ed. Rio Grande do Sul: Bookman, (2005): 441-461.

IBGE, Censo 2010. 2012. URL: http://censo2010.ibge.gov.br/

INPE, TOPODATA: Banco de dados Geomorfométricos do Brasil. 2014. URL: http://www.dsr.inpe.br/topodata/documentos.php

Komac, M. "A landslide susceptibility model using the Analytical Hierarchy Process method and multivariate statistics in perialpine Slovenia". Geomorphology. 74 (2005): 17-28. doi:10.1016/j.geomorph.2005.07.005

Mathworks. Levenberg-Marquardt backpropagation.2015, URL: http://www.mathworks.com /help/nnet/ref/trainlm.html

Malczewski, J. "Gis based multicriteria decision analysis: a survey of the literature". International Journal of Geographical Information Systems, v. 20, n. 7, fev. 2006.

Ross, J. L. S. (1994) “Análise Empírica da Fragilidade dos Ambientes Naturais e Antropizados”. Revista do Departamento de Geografia n` ${ }^{\circ}$, FFLCH-USP, São Paulo.

Ruhoff, A. L.; Penna e Souza, B. S.; Giotto, E.; Pereira, R. S. "Lógica Fuzzy e zoneamento ambiental da Bacia do Arroio Grande". Anais do XII Simpósio Brasileiro de Sensoriamento Remoto. São José dos Campos: INPE, (2004): 2355-2362. http://urlib.net/ ltid.inpe.br/sbsr/2004/11.18.21.3. 
Saaty, T. L. "How to make a decision: the hierachy process". European Journal of Operational Research. 48 (1990): 9-26 Elsevier Science Publisher, North Holland.

Saaty, T. L. Highlights and critical points in the theory and application of the Analytic Hierarchy Process. European Journal of Operational Research. 74 (1994): 426-447.

Santos, C.A. dos e Sobreira, F.G. "Análise da fragilidade e vulnerabilidade natural dos terrenos aos processos erosivos como base para o ordenamento territorial: o caso das bacias do córrego carioca, córrego do bação e ribeirão carioca na região do alto rio das velhas-MG". Revista Brasileira de Geomorfologia. 9 (2008).

Silveira, C.T. da e Oka-Fiori, C. “Análise empírica da fragilidade potencial e emergente da bacia do rio Cubatãozinho, Estado do Paraná". Caminhos de Geografia Uberlândia. 8 (2007): 1-17. ISSN 1678-6343

Souza, M. M., da Costa, L. M. e de Carvalho, D.A.S. "Utilização de ferramentas de geoprocessamento para mapear as fragilidades ambientais na área de influência direta da UHE de belo monte, no Estado do Pará”. Espaço Plural. Ano XII. 25(2011). ISSN 1518-4196

Spörl, C. "Análise da fragilidade ambiental relevo-solo com aplicação de três modelos alternativos nas altas bacias do Rio Jaguari Mirim, Ribeirão do Quartel e Ribeirão da Prata”. São Paulo, Dissertação (Mestrado) - Faculdade de Filosofia, Letras e Ciências Humanas, Universidade de São Paulo. 2000.

Tsiko, R.G. e Haile, T.S. 2011. "Integrating Geographical Information Systems, Fuzzy Logic and Analytical Hierarchy Process in Modelling Optimum Sites for Locating Water Reservoirs: a Case Study of the Debub District in Eritrea”. Water, 3 (2011): 254-290. doi:10.3390/w3010254

Triantaphyllou, E., Mann, S.H. "Using the analytic hierarchy process for decision making in engineering applications: some challenges". International Journal of Industrial Engineering: Applications and Practice. 2 (1995): 35-44.

Vahidnia, M. H.; Alesheikh, A.A.; Alimohammadi,A; e Hosseinali, F. "A GIS-based neurofuzzy procedure for integrating knowledge and data in landslide susceptibility mapping". Computers \& Geosciences. 2010. doi:10.1016/j.cageo.2010.04.004

Wang, J. J., Cheng, W. L., Liu, H. Y., Wu, y. F., e Wang, F. F. The key points to ecological planning for the improvement of urban river: A case study of Wenyu River in Beijing city. Sichuan Environment, 27(2008), 1-4 .

Wiegand, M. C.; Lima, Y. C.P.; Gomes, Q. L. de S. e Alves, N. N. L. Utilização do SIG na avaliação da Fragilidade potencial da Bacia Experimental de Aiuaba - BEA/CE. Revista de Geologia. 22 (2009).

Yamamoto, J.K. e Landim, P.M.B.. Geoestatística: conceitos e aplicações. Editora Oficina de Textos pp. 215.2013. ISBN: 9788579750779.

Recebido em Setembro de 2015.

Aceito em Dezembro de 2015. 